\title{
ADAPTAÇÃO DO MÉTODO DE CLASSIFICAÇÃO ERGONÔMICA DE TRATORES FLORESTAIS UTILIZADOS NA COLHEITA PARA COLHEDORAS DE CANA-DE-AÇÚCAR
}

\author{
Carlos Eduardo Silva Volpato ${ }^{1}$, Luis Antônio de Bastos Andrade ${ }^{2}$, Carla Bento da Silva ${ }^{3}$, \\ Jackson Antônio Barbosa ${ }^{4}$
}

\begin{abstract}
RESUMO
O presente trabalho teve como objetivo realizar uma avaliação ergonômica de uma colhedora de cana-de-açúcar pertencente à Usina da Barra, localizada no município de Barra Bonita, estado de São Paulo, em janeiro de 2007. A avaliação ergonômica foi conduzida na colhedora que apresentou a melhor produtividade na safra de 2006/2007, com base no manual Ergonomic Guidelines for Forest Machines. A melhor classificação ergonômica da colhedora (A) foi atribuída aos itens cabine, assento do operador e manual do operador. O item acesso ao posto de trabalho foi o único a ser incluído na classe C. O pior item avaliado foi a visibilidade do operador durante o corte da soqueira, sendo classificado com zero. Os demais itens avaliados se classificaram em B. Assim, a avaliação ergonômica global da máquina resultou numa classificação como B, o que indica a possibilidade de um trabalho altamente produtivo, dependendo de condições de trabalho não muito exigentes.
\end{abstract}

Palavras-chave: ergonomia, máquina agrícola, colheita mecanizada, saccharum spp.

\section{ABSTRACT \\ ADAPTATION OF THE ERGONOMIC CLASSIFICATION METHOD USED FOR FOREST HARVESTING TRACTOR TO EVALUATE SUGARCANE HARVESTER}

This study reports ergonomic evaluation of a sugarcane harvesting machine, operating in a sugarcane mill "Usina da Barra" located at Barra Bonita, São Paulo. The evaluation was done in January 2007, using the harvester that best performed during the 2006/2007 crop season. The evaluation was based on the recommendations of "Ergonomic Guidelines for Forest Machines". The maximum ergonomic points were achieved by the work post, operator seat and operator's manual. Access to work post was classified as ' $C$ '. The visibility of the stem base was the worst ranked item, at zero. All others items were classified as ' $\mathrm{B}$ '. Taking all aspects into account the harvester was classified as ' $\mathrm{B}$ ' form ergonomic point of view, which indicates potential for a highly satisfactory performance under less demanding working conditions.

Keywords: ergonomic, agricultural machinery, mechanized harvesting, saccharum spp

\footnotetext{
Recebido para publicação em 18/09/2010. Aprovado em 26/03/2012.

1- Engenheiro Florestal, Prof. Associado da UFLA, DEG, Lavras, MG, e-mail: volpato@deg.ufla.br

2- Engenheiro Agrônomo, Prof. Titular da UFLA, DAG, Lavras, MG, e-mail: laba@dag.ufla.br

3- Engenheiro Florestal, Profissional Liberal, e-mail: tayabento@hotmail.com

4- Engenheiro Agrícola, Prof. Adjunto da UFLA, DEG, Lavras, MG, e-mail: jackson@deg.ufla.br
}

210 REVENG

210-218 p. ENGENHARIA NA AGRICULTURA, VIÇOSA - MG, V.20 N.3, MAIO / JUNHO 2012 


\section{INTRODUÇÃO}

O Brasil é o maior produtor mundial de canade-açúcar, com uma produção de 437 milhões de toneladas na safra 2006/07 e uma previsão de 589 milhões de toneladas de cana-de-açúcar para a safra 2009/10. A área colhida em 2006 foi de 5,8 milhões de hectares gerando uma produção de açúcar de 30 milhões de toneladas e 17,9 bilhões de litros de álcool (AGRIANUAL, 2007).

Segundo o MAPA (2007), o Brasil possui 363 unidades produtoras entre destilarias e usinas cadastradas. A atividade sucroalcooleira absorve $3 \%$ do total de pessoas empregadas nas atividades agrícolas em todo o Brasil, somando $800 \mathrm{mil}$ cortadores de cana na safra, 200 mil operários nas agroindústrias e mais 700 mil empregos indiretos. No estado de São Paulo, maior produtor do país, o percentual de colheita mecanizada foi de $29 \%$, e deste índice 55\% sem despalha a fogo, na safra de 1999/2000 (VEIGA FILHO, 2002).

Segundo a Revista Rural (2005), existe um movimento dentro do setor sucroalcooleiro de tornar realidade a colheita mecanizada nos próximos anos. Na região Sudeste, onde se concentra mais de $70 \%$ da produção do país, cerca de $40 \%$ da colheita é mecanizada. Em outros estados como, Mato Grosso, Goiás e Mato Grosso do Sul, esses índices são maiores devido às lavouras serem mais recentes. O setor ainda depende de um amadurecimento na formação de mão-de-obra capacitada, que possibilite atender uma demanda que é crescente. A incorporação de novos conceitos de agricultura de precisão, com máquinas e implementos cada dia mais inteligentes, inclusive, com monitoramento via GPS, vai acelerar esse processo.

Para Iida (2005), a ergonomia é o estudo da adaptação do trabalho ao homem. O trabalho abrange as máquinas, equipamentos e também toda a situação em que ocorre o relacionamento entre o homem e seu trabalho. É muito mais difícil adaptar o homem ao trabalho, significando que a ergonomia parte do conhecimento do homem para fazer o projeto do trabalho, ajustando-o às capacidades e limitações humanas.

Segundo Dul e Weerdmeester (2004), o termo ergonomia é derivado das palavras gregas Ergon (trabalho) e Nomos (regras). A ergonomia estuda vários aspectos, como: postura e movimentos corporais (sentado, em pé, empurrando, puxando e levantando pesos), fatores ambientais (ruídos, vibrações, iluminação, clima, agentes químicos), informação (visão, audição etc.), controles, e mostradores. A conjugação adequada desses fatores permite projetar ambientes seguros, saudáveis, confortáveis e eficientes, tanto no trabalho quanto na vida cotidiana.

O processo de mecanização exige que o operário esteja plenamente adaptado ao posto de trabalho para poder exercer sua a função, sendo a ergonomia a ciência que estuda o melhor meio de adaptar o trabalho, seus instrumentos, equipamentos, máquinas e dispositivos ao trabalhador pela análise do ciclo de trabalho do operador. Esse estudo proporciona um ambiente de trabalho seguro e confortável.

Equipamentos adequados são os melhores recursos do trabalhador e essenciais para um trabalho confortável, mantendo a saúde e o bemestar e levando a um aumento de rendimento, diminuição dos riscos de acidentes e melhor qualidade do trabalho. As ferramentas e máquinas são, geralmente, fabricadas sem levar em consideração detalhes anatômicos do operador, posição normal de uso, distribuição ideal de peso e características específicas. Segundo Fontana e Seixas (2006), esse problema vem gradativamente melhorando a partir da última atualização da norma que trata de ergonomia no Brasil, a NR-17, publicada pelo Ministério do Trabalho e Emprego.

A ergonomia tem contribuído significativamente para a melhoria das condições de trabalho humano. Entretanto, na maioria dos países em desenvolvimento, a ergonomia é um conceito relativamente novo e essa contribuição ainda é pequena, em função do baixo número de estudos e da restrita divulgação dos seus benefícios (MINETTI, 1996).

As máquinas e ferramentas são, muitas vezes, produzidas sem levar em consideração detalhes anatômicos do operador, posição normal de uso, distribuição ideal de peso e características específicas. Muitas máquinas importadas são adaptadas às condições ergonômicas de operadores de sua região de origem, sem ao menos serem cogitadas diferenças antropométricas, de relevo, 
clima e vegetação, presentes nas condições brasileiras de trabalho (FIEDLER, 1995).

O objetivo deste trabalho foi realizar uma avaliação ergonômica de uma colhedora de canade-açúcar, enfocando-se, principalmente, nas condições mais seguras, saudáveis e confortáveis de seus operadores, facilitando a tomada de decisão na escolha de sistemas, máquinas e equipamentos de colheita de cana-de-açúcar.

\section{MATERIAL E MÉTODOS}

Os dados foram coletados na Usina da Barra, do Grupo Cosan, localizada no município de Barra Bonita, estado de São Paulo, em Janeiro de 2007. Localizado a uma latitude $22^{\circ} 29^{\prime} 41^{\prime \prime}$ sul e a uma longitude 48 $33^{\prime} 29^{\prime \prime}$ oeste. A altitude do local é de $457 \mathrm{~m}$ e sua topografia é ondulada. O clima, segundo a classificação de Köppen, é o $\mathrm{Cfb}$. A temperatura média anual mínima é de $11^{\circ} \mathrm{C}$, a média de $22{ }^{\circ} \mathrm{C}$ e a máxima de $31^{\circ} \mathrm{C}$. A precipitação média anual é em torno de $1298 \mathrm{~mm}$; o déficit hídrico é inferior a $150 \mathrm{~mm}$ anuais. O sistema de colheita é mecanizado, sendo planejado através de um software que indica qual a melhor época para se realizar essa operação para cada bloco de plantio (variedade, idade, aplicação de vinhaça, reforma, tipo de colheita, etc). A partir dessas informações, é feito um ajuste manual visando o melhor roteiro a ser seguido dentro da área operacional, para se evitar excesso de mudanças das frentes de corte. A usina dispõe de três colhedoras de cana-de-açúcar de diferentes marcas e características, sendo escolhida para a avaliação ergonômica a que apresentou a melhor produtividade na safra de 2006/2007 (932 t $\mathrm{dia}^{-1}$ ou $\left.39 \mathrm{t} \mathrm{h}^{-1}\right)$. A colhedora avaliada apresenta as características operacionais listadas no Quadro 1.

Uma vez que não existe um manual específico para colhedoras de cana-de-açúcar, a máquina em questão foi avaliada segundo as diretrizes ergonômicas contidas no manual de classificação ergonômica Ergonomic Guidelines for Forest Machines (SKOGFORSK, 1999). Desta forma, os seguintes itens foram avaliados:

1. Acesso ao posto de trabalho - observação e medida dos meios de acesso;

2. Cabine - medição das dimensões da cabine (altura e largura);

3. Visibilidade - medição das dimensões dos vidros e espelhos disponíveis;

4. Iluminação - número de faróis, seu direcionamento e capacidade de iluminação;

5. Assento do operador - medição das alturas do assento do operador e observação de presença ou não de apoio de braços, encosto de cabeça, entre outros;

6. Comandos e instrumentos - observação visual de todos os comandos e instrumentos e suas respectivas funções (com auxílio do manual do operador);

7. Ruído - medição dos decíbeis com decibelímetro marca SPER Scientific, modelo SPER 840029. A medida foi realizada à distância de um palmo do ouvido $(0,2 \mathrm{~m})$ do operador, sendo feitas 10 repetições, medidas em intervalos de 30 segundos da mesma operação. A obtenção de valores médios de nível de ruído foi feita por meio do cálculo do nível equivalente (Leq), conforme NR-15. Este valor corresponde ao valor integrado dos níveis de ruído isolados obtidos em intervalos de tempo constantes. Na obtenção de valores de nível de

Quadro 1. Dados operacionais sobre a colhedora de cana-de-açúcar avaliada na Usina da Barra, Barra Bonita, SP

\begin{tabular}{cc}
\hline Parâmetro & Característica Operacional \\
\hline Sistema de locomoção & Esteira \\
Motor & 6 cilindros \\
Potência do motor & $332 \mathrm{cv}, 2100 \mathrm{rpm}$ \\
Admissão de ar & Por turbo-compressor \\
Pós-resfriamento & $\mathrm{Ar}-\mathrm{ar}$ \\
Combustível & Óleo diesel \\
Tanque de combustível & 568 litros (150 galões) \\
Bateria & 2 unidades, $12 \mathrm{~V}$ cada \\
\hline
\end{tabular}

\section{REVENG}


pressão sonora com o decibelímetro, durante certo intervalo de tempo, ocorrem variações nestes valores, visto que este aparelho apresenta o resultado instantâneo de pressão sonora. O Leq retorna um valor único que, caso se mantivesse constante durante o mesmo intervalo de tempo, resultaria na mesma quantidade de energia sonora presente durante a coleta dos dados variados anteriormente. Este valor é obtido por meio da Equação 1:

$$
\mathrm{L}_{\mathrm{eq}}=10 \cdot \log \left(\frac{1}{\mathrm{n}} \cdot \sum_{\mathrm{i}=1}^{\mathrm{n}} \mathrm{f}_{\mathrm{i}} \cdot 10^{0,1 \cdot \mathrm{L}_{\mathrm{i}}}\right)
$$

em que

$\mathrm{L}_{\text {eq }}=$ nível de ruído equivalente, em $\mathrm{dB}(\mathrm{A})$;

$\mathrm{n}=$ número de medições válidas;

$\mathrm{fi}=$ freqüência do ruído $\mathrm{Li} ; \mathrm{e}$

$\mathrm{Li}=$ nível de ruído medido a cada 10 segundos, em $\mathrm{dB}(\mathrm{A})$.

8. Controle de clima na cabine - observação da presença ou ausência do climatizador de ar na cabine, suas velocidades e termostato;

9. Exaustão de gases e poeiras - observação do design do escapamento e o sentido de direcionamento da fumaça;

10. Manual do operador - observação no manual do operador das instruções escritas e fichas de recomendação.

Em função do exame desses itens, as colhedoras foram enquadradas nas classes mostradas no Quadro 2, de acordo com o manual de Skogforsk (1999).

As diretrizes são escritas com referência à classe A e, portanto, descrevem os requerimentos mais restritos. Em algumas seções, que requerem o uso de equipamento de medição que não está prontamente disponível, as diretrizes foram divididas em duas seções, uma opcional, baseada em medições, e a outra obrigatória, baseada na avaliação subjetiva, que tem que ser feita em qualquer caso.

Os itens sujeitos a avaliação qualitativa foram classificados em relação à sua adequação aos padrões ergonômicos recomendados. $\mathrm{O}$ dado relativo a ruído (avaliação quantitativa) foi confrontado com as diretrizes ergonômicas e com

Quadro 2. Classificação de máquinas agrícolas quanto a características ergonômicas

\section{Classe}

A

C

$\mathrm{D}$

0 (Zero)

\section{Características}

Trabalho altamente produtivo em todos os tipos de terrenos e povoamentos. Alto nível, tanto de segurança ativa quanto passiva. Trabalho de manutenção fácil, direto e seguro.

Trabalho altamente produtivo, mas sob condições mais fáceis do que as da Classe A. Alto nível de segurança ativa e passiva, mas não do mesmo padrão da classe A.

Condições mais fáceis e/ou durações mais curtas do que na Classe B. Nível alto de segurança ativa e passiva, mas não do mesmo padrão da Classe B.

Condições mais fáceis e/ou durações mais curtas do que na Classe C. Nível alto de segurança ativa e passiva, mas não do mesmo padrão da Classe $\mathrm{C}$.

A máquina não satisfaz os requerimentos de segurança e regulamentos ou tem defeitos tão sérios que o operador corre um alto risco de se ferir. A máquina não deve ser utilizada até que os defeitos tenham sido corrigidos e preencha os critérios especificados em uma das outras classes (A-D). 
os limites máximos de exposição determinados pelas Normas Regulamentadoras do Ministério do Trabalho (SEGURANÇA E MEDICINA DO TRABALHO, 1992).

\section{RESULTADOS E DISCUSSÃO}

As colhedoras utilizadas na colheita de canade-açúcar foram avaliadas sob o ponto de vista ergonômico, seguindo o checklist recomendado por Skogforsk (1999).

Os degraus são em número de seis, sendo cinco de ferro (com distâncias de $32 \mathrm{~cm}$ do primeiro ao segundo, $36 \mathrm{~cm}$ do segundo ao terceiro e 35 $\mathrm{cm}$ entre degraus, do terceiro ao sexto), sendo o primeiro de borracha. A distância desse degrau de borracha ao solo é de $62 \mathrm{~cm}$. A altura da plataforma ao chão é de $2,35 \mathrm{~m}$.

$\mathrm{O}$ acesso à cabine é feito pelos dois lados, pela plataforma que circunda a cabine; mas a porta abre apenas pelo lado direito da máquina; a abertura da porta é lateral e de fácil abertura, de dimensões de maior largura de $1,02 \mathrm{~m}$ e altura de 1,44 m, havendo uma janela traseira de dimensões de maior largura $97 \mathrm{~cm}$ e altura $91 \mathrm{~cm}$. A cabine é fechada com vidros.

De acordo com Skogforsk (1999), o acesso ao posto de trabalho encontra-se fora dos padrões ergonomicamente aceitos, ou seja, não está dentro da classificação tida como ótima (classe A). Também, segundo as diretrizes citadas, o operador deve ser capaz de descer da máquina de frente, o que significa que a essa deveria estar equipada com um lance de escadas seguro, o que não acontece nesse caso, onde o operador tem que descer da máquina de costas, dificultando a descida e trazendo perigo para o operador. Assim, o acesso ao posto de trabalho foi enquadrado na classe $\mathrm{C}$.

A cabine tem altura de $1,54 \mathrm{~m}$, de piso emborrachado, coberto com tapete de borracha. Os pedais são de ferro, fixos, dois do lado direito do operador, sem quinas vivas, não vazados, de tamanho $8 \times 12 \mathrm{~cm}$ e distantes $4 \mathrm{~cm}$ um do outro.

Isso está de acordo com o recomendado por Skogforsk (1999), uma vez que o operador é capaz de assumir uma posição confortável, proporcionando uma boa visibilidade e com os controles a uma distância conveniente. Operadores de diferentes estaturas são capazes de operar a máquina e adotar diferentes posturas.

Observou-se uma cabine extremamente espaçosa, podendo o operador adotar posições confortáveis de trabalho. A cabine foi classificada como de classe $\mathrm{A}$.

O pára-brisa é inteiro, com dimensões de 1,60 $\mathrm{m}$ de largura e 1,35 de altura. Os retrovisores são em número de quatro (dois de cada lado), com dimensões de $17 \mathrm{~cm}$ x $23 \mathrm{~cm}$ e $18 \mathrm{~cm}$ x $35 \mathrm{~cm}$. Seguindo as normas de classificação de Skogforsk (1999), o operador tem uma visão livre da zona de operação, sem ter que ajustar sua postura; o vidro da janela é de fácil limpeza. A visibilidade, desta forma, deveria ser classificada como B.

Entretanto, diferentemente do que acontece com a colheita florestal, onde o operador tem uma visão mais nítida do local a ser cortado, na canade-açúcar isso não acontece, pois o operador não consegue enxergar a soqueira. Ele simplesmente ajusta a altura de corte e enquadra colhedora na linha de plantio. Sendo assim, a visibilidade para essa condição foi classificada como zero.

A máquina tem seis faróis dianteiros de tamanhos iguais, três de cada lado (luz de estrada), dois faróis intermediários de tamanhos iguais (luz de campo) e 2 faróis traseiros (um de cada lado, denominados de farol de campo). A cabine tem luz interna. Plataforma e degraus não têm iluminação.

Segundo Skogforsk (1999), se a iluminação não é suficientemente forte, a luz fornecida não será boa o suficiente para o operador focalizar detalhes e também irá reduzir seu reconhecimento de cores e taxa de percepção. Uma taxa de percepção aceitável é de 50 lux (fluxo luminoso incidente por unidade de área de uma superfície). Como no caso analisado não foi utilizado um luxímetro, uma classificação mais subjetiva foi usada para realizar a classificação desse item. $\mathrm{O}$ autor recomenda que a iluminação em uma máquina deva possibilitar ao operador desempenhar todas as tarefas que podem ser feitas a luz do dia. A intensidade luminosa deve ser alta o suficiente e a luz deve ser direcionada de forma tal que não haja ofuscamento por contrastes ou reflexos. Esse item foi classificado como C.

A altura do assento do operador é de $53 \mathrm{~cm}$ (base), sem encosto de cabeça. O filtro do ar condicionado encontra-se embaixo desse assento. 
A colhedora também apresenta um assento auxiliar, de treinamento, com $49 \mathrm{~cm}$ de altura (base), também sem encosto. $\mathrm{O}$ material utilizado em ambos os assentos é um estofado comum, de nylon. A distância do assento ao pára-brisa é de 55 $\mathrm{cm}$. A distância do vidro traseiro até o pára-brisa é de $1,46 \mathrm{~m}$.

$\mathrm{O}$ assento do operador tem um sistema de suspensão a ar e um compressor elétrico independente para ajustar a suspensão de acordo com a altura e o peso do operador. As regulagens do assento são as seguintes: Amortecedor vertical de choques; Regulagem da altura; Regulagem de avanço/recuo; Inclinação do fundo do assento; Regulagem da suspensão, avanço e recuo do fundo do assento; Inclinação do encosto; Regulagem de apoio lombar do encosto; Regulagem de apoio de braço esquerdo; Regulagem do apoio de braço direito e console de controle. Possuem cinto de segurança de acordo com a norma.

O que foi observado está de acordo com o descrito por Arbetsmiljoinstituted et al. (1990), que relatam que o assento deve ter ajuste em altura, distância e comprimento, sendo que o apoio de braços deve também ser ajustável em altura.

O assento do operador também está de acordo com Skogforsk (1999), pois esse item e os descansos de braço são convenientes para operadores de diferentes estaturas, permitindo uma ampla variedade de posições sentadas e é prontamente ajustável. Os suportes de braço oferecem apoio, não restringindo os movimentos, podendo-se classificar como ergonomicamente ótimo, nesse aspecto, segundo as diretrizes ergonômicas. Esse item foi enquadrado na classe $\mathrm{A}$.

A máquina apresenta os seguintes itens: painel principal, painel de controle da coluna lateral direita, painel de controle da coluna lateral esquerda, duas alavancas de controles de direção e painel superior.

O painel principal contém o joystick de subida e descida do cortador de base, o interruptor liga/ desliga do controle automático do corte de base, manípulo de ajuste da pressão de corte do cortador de base, interruptor de parada de emergência da função de colheita, interruptor de variação da pressão alta/baixa, manípulo de ajuste da sensibilidade do controle automático do corte de base, interruptor de redefinição (reset da parada de emergência), rotação do cortador de pontas, rotação do bojo do extrator primário, inclinação do divisor de linhas direito, rotação da faca lateral direita, interruptor de aceleração do motor, saída elétrica para acessório, rotação da faca lateral esquerda subida/descida do elevador, avanço/recuo do elevador, controle da rotação do ventilador do extrator primário, inclinação do divisor de linhas esquerdo e rotação do cortador de base, picador, rolos alimentadores e divisor de linhas. Ainda constam a luz indicadora de sistema ativo do corte de base e a luz indicadora de aumento de pressão do picador ou falhas no sistema.

O joystick apresenta as seguintes funções e controles: subida do cortador de base, descida do cortador de base, descida e subida do divisor de linhas direito, subida e descida do divisor de linhas esquerdo, abertura e fechamento da aba do cesto, subida e descida do cortador de pontas, rotação à esquerda e à direita do bojo do extrator secundário e buzina.

No painel de controle da coluna lateral direita existem as seguintes funções e indicações: luz indicadora de advertência do motor, luz indicadora da parada do motor, luz indicadora de advertência do freio de estacionamento, luz indicadora de advertência de alta pressão no ar condicionado, luz indicadora de advertência de obstrução do filtro de óleo hidráulico, luz indicadora de advertência de obstrução do filtro de ar, velocímetro, chave de ignição, alarme sonoro, indicador da temperatura do líquido de arrefecimento e monitor de diagnóstico do sistema eletrônico do motor.

No painel de controle da coluna lateral esquerda constam as seguintes informações e funções: indicador de altura do cortador de base, indicador de pressão do cortador de base, indicador de temperatura do óleo hidráulico e luz indicadora de baixo nível de óleo hidráulico.

Por ser de esteira, a máquina possui duas alavancas de controle para avanço e direção. Quando as duas alavancas estão centralizadas, a colhedora está em neutro. O movimento para frente é feito ao empurrar ambas para a frente. O movimento para trás é feito ao puxar ambas as alavancas para trás. Quando a alavanca esquerda ou direita é empurrada para frente, a esteira correspondente irá girar para 
trás. Na alavanca direita está o controle do elevador ligado ou desligado: o botão (A) liga ou desliga o elevador na direção para frente.

No painel superior encontram-se os seguintes interruptores e controles: interruptor do piscaalerta, interruptor da luz de estrada, interruptor da luz de campo, interruptor do farol de campo (compartimento do motor), rolo tombador ajustável, extrator primário ligado/desligado, extrator secundário ligado/desligado, controle da temperatura de aquecimento, interruptor do ar condicionado, ventilador do ar condicionado, contador de horas de funcionamento do elevador, interruptor do pisca direcional e interruptor do limpador/lavador de pára-brisa dianteiro.

Verificou-se que algumas alavancas e botões usados freqüentemente estão emuma área de alcance ótimo. Contudo, algumas informações podem não ser visualizadas corretamente, dado o tamanho de suas letras e a distância do assento do operador à informação precisa. Os comandos e instrumentos não são classificados como ergonomicamente perfeitos, pois nem todas as alavancas oferecem uma manipulação confortável e apoio para a mão, sendo que algumas posições não são totalmente ajustáveis para diferentes padrões de trabalhadores, segundo as recomendações de Skogforsk (1999). Esse item foi classificado como B.

Com a máquina apenas ligada, em rotação normal, foi encontrado um valor $\mathrm{L}_{\text {eq }} 80,11 \mathrm{~dB}(\mathrm{~A})$ na cabine do operador. A mesma verificação foi feita com a máquina em operação, com um total de dez repetições, tendo sido encontrado um valor $\mathrm{L}_{\text {eq }}$ de 72,13 dB(A). De acordo com a portaria CLT 3214-NR 15 (ABNT, 1987) para ruídos contínuos, esses valores estão dentro das normas de segurança no trabalho, que estabelece o valor de $85 \mathrm{~dB}(\mathrm{~A})$ como máxima exposição permissível para uma jornada de 8 horas.

Saliba (2001) também define como limite de tolerância para ruído contínuo/intermitente o valor de $85 \mathrm{~dB}(\mathrm{~A})$ para a exposição diária de 8 horas. Esse item foi classificado como de classe B.

A climatização é regulável através de termostato próprio, com três velocidades do ar, e resposta rápida a mudanças de temperaturas. Os controles são de fácil operação, tendo esse item sido enquadrado como de classe B.

Foram constatados que o escapamento acima do nível da cabine localiza-se no meio da colhedora, portanto prevenindo a entrada de fumaça na cabine. Para Arbetsmiljoinstituted et al. (1990), o projeto da cabine deve manter do lado externo os gases de exaustão e poeira. Assim, as condições encontradas estão dentro dos limites aceitáveis. As diretrizes descrevem como ergonomicamente aceitável quando o desenho da cabine evita a entrada de fumaça, o sistema de exaustão está livre de vazamentos e o cano de descarga está localizado bem longe da entrada de ar da cabine. Verifica-se que os padrões encontrados estão dentro dos limites ergonomicamente classificados como não muito satisfatórios. Esse item foi considerado como de classe B.

$\mathrm{Na}$ análise das características do manual do operador, foi constatado estar dentro das normas ergonômicas de Skogforsk (1999), contendo adequadas instruções para a manutenção da máquina de acordo com as horas trabalhadas. O manual tem tabelas de conteúdo e índice compreensíveis,

Quadro 3. Resumo da classificação ergonômica da colhedora de cana-de-açúcar da Usina da Barra, Barra Bonita, SP.

\begin{tabular}{|c|c|}
\hline Item avaliado & Classe \\
\hline Acesso à cabine & $\mathrm{C}$ \\
\hline Cabine & A \\
\hline Visibilidade da soqueira pelo operador & Zero \\
\hline Iluminação & $\mathrm{B}$ \\
\hline Assento do operador & A \\
\hline Controles e operação da máquina & B \\
\hline Ruído & B \\
\hline Controle de clima na cabine & B \\
\hline Exaustão de gases e poeiras & B \\
\hline Manual do operador & A \\
\hline
\end{tabular}

\section{REVENG}


é claramente ilustrado, é fácil de ler na linguagem local e usa terminologia e símbolos padronizados. Esse item recebeu a classificação de A. O Quadro 3 apresenta-se um resumo da classificação ergonômica da colhedora por item avaliado.

Portanto, a colhedora apresentou o predomínio de itens com classificação melhor, sendo sua avaliação final como de classe B. Assim, a máquina possibilita um trabalho altamente produtivo, mas sob condições mais fáceis do que as da Classe $\mathrm{A}$ (por exemplo, menor ritmo, trabalho menos exigente, terreno, povoamento e condições climáticas mais fáceis), com alto nível de segurança ativa e passiva, mas não do mesmo padrão da classe $\mathrm{A}$.

Uma das características desse manual de classificação ergonômica é que os elementos do design e função de uma máquina que influenciam as condições de trabalho do operador estão divididos em cinco classes pré-definidas. Isso pede uma medida de julgamento subjetivo, uma vez que é impossível definir claramente as classes. É necessário, para se proceder a uma avaliação consistente, algum conhecimento de ergonomia. Tanto critérios técnicos quanto subjetivos são fornecidos para cada classe. O objetivo é que a avaliação seja a mesma, não importando quem a está fazendo. Por essa razão, métodos padronizados devem ser utilizados sempre que possível, tanto para medir quanto para interpretar os resultados.

O princípio da classificação é que o impacto de uma máquina na saúde e no bem estar do operador deveria ser o mesmo, não importando a classe onde o item avaliado foi colocado. Isso pressupõe que a máquina esteja sendo usada para o propósito para o qual foi projetada e que foram levados em consideração a duração, o movimento (tempo) e a dificuldade do trabalho. O próprio autor da classificação (SKOGFORSK, 1999) reconhece que muitos dos critérios da classe A não serão preenchidos ainda por alguns anos.

\section{CONCLUSÕES}

- A máquina avaliada apresenta boas condições de trabalho sob o ponto de vista ergonômico, obtendo classificaçao final B;

- Sob o ponto de vista ergonômico, a colhedora tem condições de melhorias, principalmente nos itens classificados como C e D.

- Em relação ao item visibilidade da soqueira classificado como zero, o potencial de melhora envolve mudanças estruturais na posição da cabine; e

- A máquina avaliada possibilita o alcance de índices de produtividade adequados na colheita de cana-de-açúcar, dependendo, porém, de condições de trabalho, como características da área de colheita, clima, etc., podendo-se incluir uma melhor adequação operador/máquina.

\section{REFERÊNCIAS BIBLIOGRÁFICAS}

AGRIANUAL 2007. Anuário da agricultura brasileira. São Paulo: FNP, 2007. p.237-268.

ARBETSMILJOINSTITUTED; FORSKINGSS TIFTELSEN SKORGSARBETEN; SLU SKOGSHOGSKOLAN. An ergonomic checklist for forestry machinery. Oskarshamn, 1990.43p.

DUL, J.; WEERDMEESTER, B. Ergonomia prática. $2^{\mathrm{a}}$ Edição. Edgard Blücher, São Paulo, 2004. 137 p.

FIEDLER, N.C. Avaliação ergonômica de máquinas utilizadas na colheita de madeira. 1995. 126f. Dissertação (Mestrado em Ciencias Florestais) Universidade Federal de Viçosa, 1995.

FONTANA, G.; SEIXAS, F. Levantamento antropométrico de operadores brasileiros de tratores florestais "Forwarders" e "Skidders". Revista Engenharia Rural, Piracicaba, v.17, n.1, p.41-46, setembro, 2006.

GARROW, J.S. Treat obesity seriously: a clinical manual. $2^{\mathrm{a}}$ Edition. Edinburg: Churchill Livingstone, 1981. 365p.

IIDA, I. Ergonomia: projeto e produção. $2^{\text {a }}$ Edição revista e ampliada. São Paulo: Edgard Blucher, 2005. 614p.

MAPA- Ministério da Agricultura, Pecuária e 
Abastecimento. Cana-de-açúcar e agroenergia: Usinas e destilarias cadastradas. Disponível em: www.agricultura.gov.br Acesso em: 28 de mar. 2007.

MINETTI, L.J. Análise de fatores operacionais e ergonômicos na operação de corte florestal com motosserra. 1996. 211 f. Tese (Doutorado em Ciências Florestais) - Universidade Federal de Viçosa, 1996.

REVISTA RURAL. Cana: colheita mecanizada. 2005. Disponível em: www.revistarural.com.br/ Edicoes2005/artigos/rev92cana.htm. Acesso em: 28 mar. 2007.

SALIBA, T. M. Manual prático de avaliação e controle de ruído: PPRA. $2^{\mathrm{a}}$ ed. São Paulo: LTR, 2001. 118p.
SILVA, C.B. Avaliação ergonômica de máquinas utilizadas na colheita de Eucalyptus. 2002. 116 f. Dissertação (Mestrado em Engenharia Florestal) - Universidade Federal de Lavras, 2002.

SKOGFORSK - The Forestry Research Institute of Sweden. Ergonomic guidelines for forest machines. Uppsala, Sweden: Swedish National Institute for Working Life, 1999. 86p.

VEIGA FILHO, A. de A. A Substituição De Empregos Por Máquinas: Uma Simulação para o corte da cana-de-açúcar em São Paulo. 2002. Disponível em: http://www.iea.sp.gov.br/ out/verTexto.php?codTexto=111 Acesso em: 31 mar. 2007 